\title{
Synchronous Generation of Nano- and Microscaled Hierarchical Porous \\ Polyelectrolyte Multilayers for Superwettable Surfaces
}

Jing Yu, Songyang Han, Joung Sook Hong, Oishi Sanyal, Ilsoon Lee*

Department of Chemical Engineering and Materials Science, Michigan State University,

Michigan State University, East Lansing, Michigan 48824, USA

\section{Supporting Information}

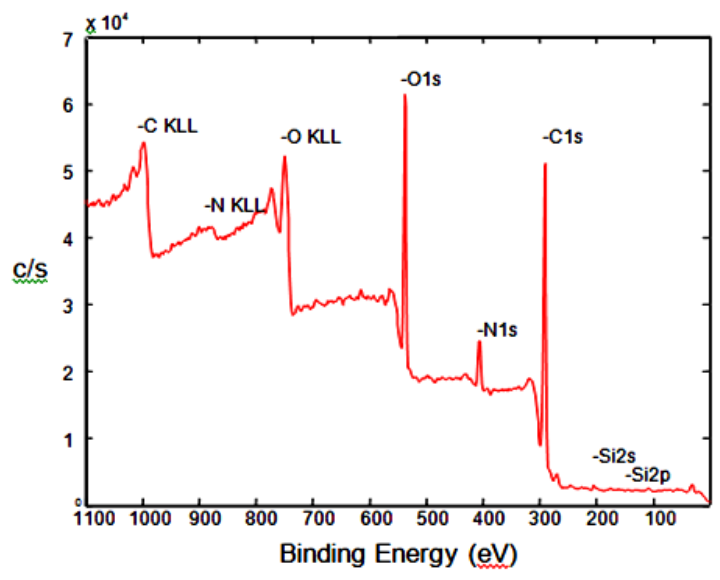

(a)

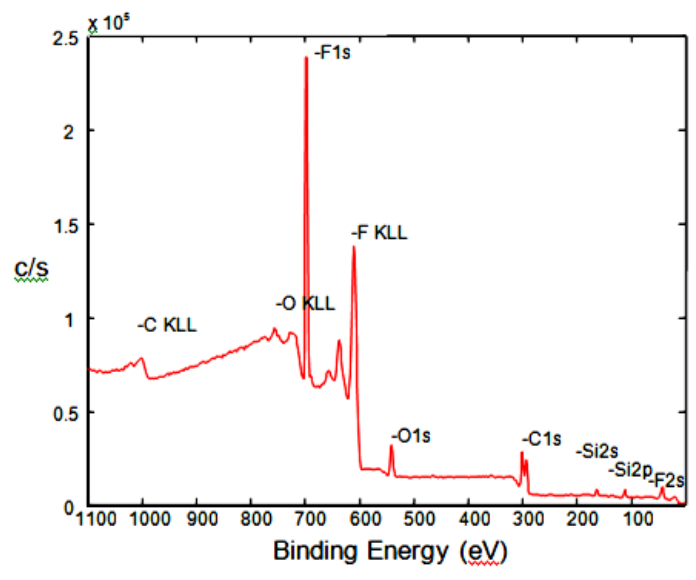

(b)

Figure S1. XPS spectra of porous $\left(\mathrm{PAH}_{\mathrm{H}} / \mathrm{PAA}_{\mathrm{L}}\right)_{20.5}$ film before (a) and after (b) the CVD process. 